\title{
SEALING ABILITY OF NOVEL HYDROPHILIC SINGLE-CONE OBTURATION SYSTEMS IN AN OVAL CANAL: AN IN-VITRO GLUCOSE LEAKAGE STUDY
}

Vibha Hegde ${ }^{1}$, Shashank Arora ${ }^{2}$

${ }^{1}$ Professor \& Head, Department of Conservative Dentistry \& Endodontics, YMT Dental College and Hospital, Mahrashtra, India ${ }^{2}$ PG Student, Department of Conservative Dentistry \& Endodontics, YMT Dental College and Hospital, Mahrashtra, India

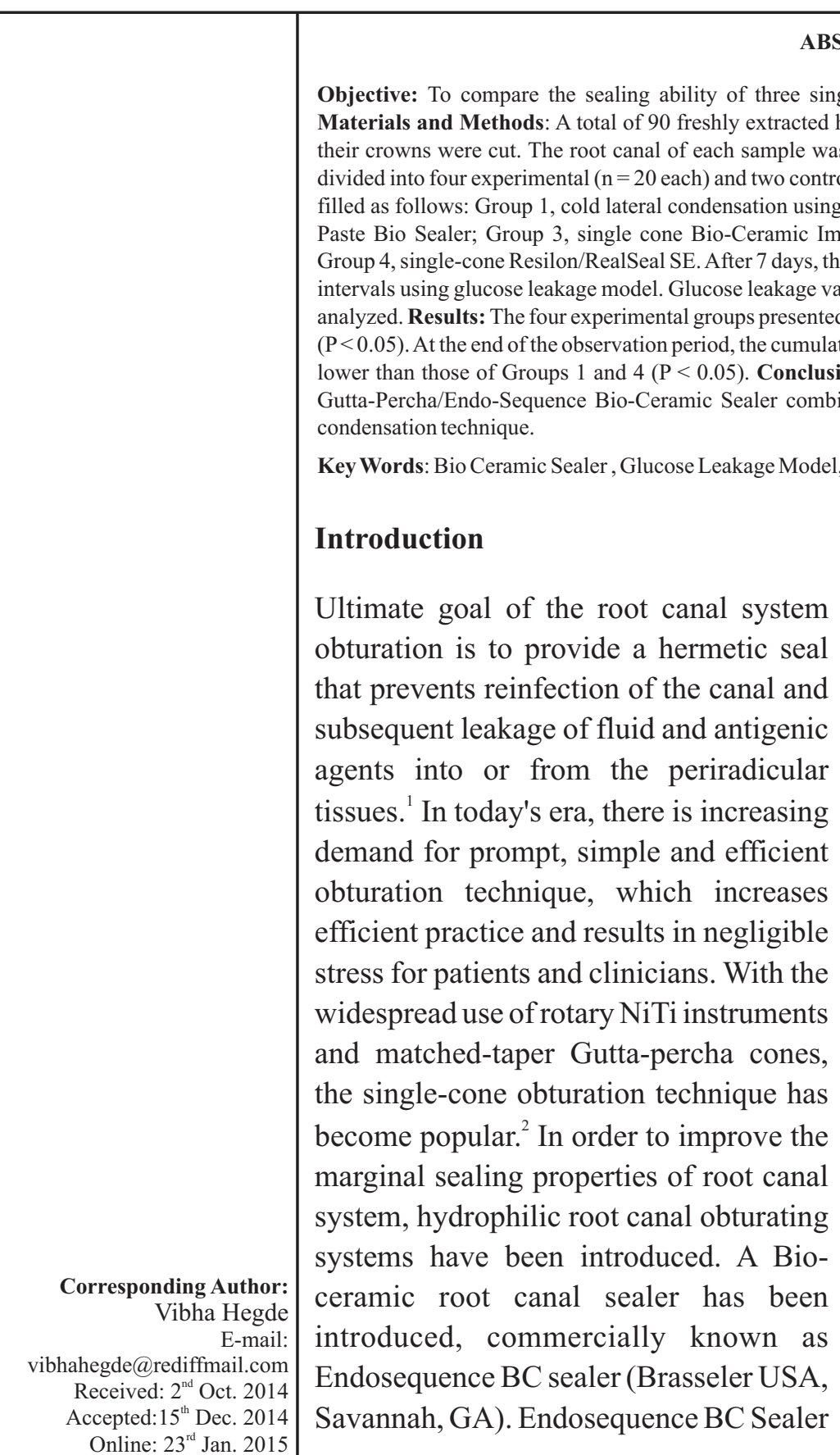

BSTRACT

Objective: To compare the sealing ability of three single-cone obturation systems using a glucose leakage model. Paste Bio Sealer; Group 3, single cone Bio-Ceramic Impregnated Gutta-Percha/Endo-Sequence Bio-Ceramic Sealer Group 4, single-cone Resilon/RealSeal SE. After 7 days, the sealing ability of root canal fillings was tested at different time (a) $(\mathrm{P}<0.05)$. At the end of the observation period, the cumulative glucose leakage values of Groups 2 and 3 were significantly

\section{Introduction}

Ultimate goal of the root canal system tic seal that prevents reinfection of the canal and subsequent leakage of fluid and antigenic gents into or from the periradicula tissues. In today's era, there is increasing demand for prompt, simple and efficient increases stress for patients and clinicians. With the widespread use of rotary NiTi instruments and matched-taper Gutta-percha cones, the single-cone obturation technique has become popular. ${ }^{2}$ In order to improve the marginal sealing properties of root canal torating systems have been introduced. A Bioceramic root canal sealer has been introduced, commercially known as Savannah, GA). Endosequence BC Sealer is a premixed and injectable endodontic sealer, and its nanoparticle size sanctions it to flow into canal irregularities and dentinal tubules. It is hydrophilic and uses moisture in dentinal tubules to initiate and complete its setting reaction. In addition, no shrinkage occurs on setting, resulting in a gap-free interface between the guttapercha, sealer, and dentin. ${ }^{3}$ The most recent obturating system is the SmartSeal System which is composed of Cpoints and Smart-Paste Bio sealer. The Cpoints have been designed to expand laterally utilizing the inherent moisture present in the instrumented root canal space. ${ }^{4}$ The ReaSeal SE system consists of a self-etching methacrylate sealer and Resilon core material. It reduces the application steps of the original epiphany system, thus becoming a more operator friendly and bonds to both the Resilon core and radicular dentin through hybrid layers on both substrates leading to a 
mono-block unit, which may prevent leakage and improve the root strength. ${ }^{5-7}$ Canals have different configurations, and as a consequence of these features the quality of the filling of the root canal space may vary owing to the shape of the cross-section. Mauger et $\mathrm{al}^{8}$ stated that long oval canals are present in $80 \%$ of mandibular incisors. After preparation, the ovalshaped canals may leave uninstrumented and unfilled recesses which have the potential to promote leakage. Juhasz et al. ${ }^{9}$ reported that the root canal form influenced short-term sealing ability, and $\mathrm{Wu}$ and Wesselink ${ }^{10}$ demonstrated that uninstrumented recesses in oval canals were unfilled or incompletely filled by cold lateral condensation of gutta-percha. The problems associated with root fillings of oval root canals was discussed in a recent study by De-Deus et al. ${ }^{11}$ The sealing ability is a basic feature that needs to be tested for every root canal filling material or technique. Various test methods have been described to evaluate the quality of seal by such methods as dye penetration, radioactive isotopes test, bacteria or bacterial metabolites leakage test, electrochemical technique, and fluid filtration. ${ }^{12}$ However, the published reports often reach different or even conflicting conclusions. As pointed out by Wu and Wesselink, there was a high level of variation in these results and it was difficult to draw firm conclusions as to which filling technique or material was the best in sealing the root canal system. It was suggested that more studies should be devoted to perfecting microleakage methodology. ${ }^{13}$ These methods include dye penetration, spectrometry of radioisotopes, fluoro-metric and electrometric methods, bacterial penetration and fluid transport model. ${ }^{12} \mathrm{Xu}$ et al discussed a new non-destructive model that measures the leakage of glucose molecules quantitatively by using a spectrophotometer. The aim of the present study was to evaluate corono-apical micro-leakage along root canal fillings using glucose leakage model by comparing three matched-taper single-cone filling systems with cold Gutta-percha lateral compaction technique using glucose leakage model at different time intervals.

\section{MATERIALS AND METHOD Samples preparation}

One hundred fifty left and right mandibular incisors were selected and autoclaved. Periapical radiographs of each tooth were taken in both the buccolingual and mesiodistal planes. Teeth with oval-shaped canals were selected only when the ratio of the long: short diameter was $\geq 2.5$ at $5 \mathrm{~mm}$ from the apex (Wu \& Wesselink 2001, De-Deus et al. 2006). Teeth presenting with an isthmus, lateral and accessory canals, or more than one canal were excluded from the sample. Therefore, only 90 mandibular incisors were classified as single oval-shaped canals and were stored in $10 \%$ neutral formalin. The crowns were cut with help of diamond disk below the cemento-enamel junction so that the length of roots was standardized at $15 \mathrm{~mm}$. The working length was determined and the canals were instrumented by Pro-Taper NiTi rotary instrument (Dentsply Maillefer) to size F2 using the crown-down technique after which circumferential filling was done with $20 \# \mathrm{~K}$ File. The canals were irrigated after using each file with $5 \mathrm{ml}$ of $3 \%$ sodium hypochlorite $(\mathrm{NaOCl})$ solution using a syringe and 29G needle (NaviTip; Ultradent, South Jordan, UT). . After finishing the instrumentation, the prepared canals were rinsed with $5 \mathrm{ml}$ of $17 \%$ ethylenediaminetetraacetic acid (EDTA) solution for 2 min followed by $10 \mathrm{ml}$ distilled water as final irrigation to remove any traces of $\mathrm{NaOCl}$.

\section{Samples grouping and root canal obturation}

After drying all canals with absorbent paper points, the samples were divided according to the obturation technique and materials into four experimental groups of 20 samples each and two control groups of 5 samples each. Samples in the negative control group did not receive root canal fillings while in the positive control group they were obturated with a single-cone Gutta-percha size 25/0.06 but without sealer placement. In Group 1, AH Plus sealer was mixed according to the manufacturer's instructions and applied into the prepared root canal using a lentulo spiral size 25. A master Guttapercha cone of size $25 / 0.06$ was coated with sealer and placed into the root canal to the full working length. Lateral condensation was achieved using size 25/0.02 standardized Guttapercha cones and size 25/.04 finger spreader (Dentsply Maillefer). Excess Gutta-percha was cut at the orifice level with a flame-heated hand plugger and vertically compacted. In the other experimental groups (Singlecone obturation technique), each sealer was prepared 
and placed into prepared canals according to manufacturer's instructions. The tip of the matched taper cone (C-Points/Bio-Cearmic Impregnated Gutta-percha or RealSeal point) was dipped into the sealer and placed slowly in up and down motion until reaching the full working length. The coronal excess of the master cone was pre-cut to coronal orifice using a scissors at a predetermined length. In the Real Seal group, the coronal surface of the obturation was light cured after $5 \mathrm{~min}$ for $40 \mathrm{~s}$. All samples were incubated for 1 week at $37^{\circ} \mathrm{C}$ and $95 \%$ humidity to allow complete setting of sealers.

\section{Microleakage measurement}

The roots in the experimental and positive control groups were coated with triple layers of nail varnish, except at the coronal end and apical $1 \mathrm{~mm}$ of the root end. The roots in the negative control group were entirely covered with nail varnish. Microleakage along the root canal was evaluated using the glucose leakage model as described by $\mathrm{Xu}$ et al. ${ }^{5}$ The concentrations of leaked glucose $(\mathrm{mg} / \mathrm{dl})$ were measured after 1 day and then after 1, 2, 3, 4 and 6 weeks with a Glucose kit (Glucose Liquid, Quimica Clinica Applicada S.A) in a spectrophotometer (Beckman Du 520, Coulter, Germany) at a wave length of $505 \mathrm{~nm}$.

\section{Statistical analysis}

The results were statistically analyzed by KruskalWallis and Mann-Whitney tests. To compare leakage at different times within each group, Freidman and Wilcoxon signed ranks tests were used. All level of statistical significance was set at a P value less than 0.05 .

\section{RESULTS}

The negative control group showed no detectable glucose leakage throughout the experiment while the positive control group had immediate substantial glucose leakage, which increased over time. This indicates that the seal of the glucose leakage system was effective and reliable. The mean values and statistical comparisons between the experimental groups at each time interval are given in Table 1. After the 1st day onward, there were significant differences between the experimental groups (Kruskal Wallis test, $\mathrm{P}<0.05)$. The results of the Mann-Whitney test indicated that there was no significant difference between Groups 2 and 3 throughout the test period. After the 1st day, the highest glucose leakage was observed in Group 1. After the 1st week, the lowest glucose leakage was observed in the 3rd Group. Starting from the $3 \mathrm{rd}$ week onward, the lowest glucose leakage was observed in the Groups 2 and 3. Statistical comparisons between glucose leakage values within each group are presented in Table 2. There was a progressive and significant increase in the glucose leakage values in all experimental groups (Friedman test, $\mathrm{P}<0.05)$.

Table 1: Glucose Leakage at various time Intervals

\begin{tabular}{|c|c|c|c|c|c|c|}
\hline Groups & Day 1 & Week1 & Week2 & Week3 & Week4 & Week 6 \\
\hline Group 1 & $0.52 \pm 1.31^{\mathrm{a}}$ & $5.02 \pm 1.51^{\mathrm{a}}$ & $11.02 \pm 2.61^{\mathrm{a}}$ & $13.32 \pm 0.62^{b}$ & $15.66 \pm 4.57^{\mathrm{a}}$ & $18.43 \pm 3.83^{a}$ \\
\hline Group2 & $0.00 \pm 0.32^{\mathrm{b}}$ & $1.34 \pm 1.33^{\mathrm{b}}$ & $5.62 \pm 1.53^{b}$ & $7.72 \pm 0.11^{\mathrm{a}}$ & $7.98 \pm 1.93^{b}$ & $10.22 \pm 3.51^{b}$ \\
\hline Group3 & $0.00 \pm 0.00^{\mathrm{b}}$ & $1.23 \pm 1.21^{\mathrm{b}}$ & $6.02 \pm 2.72^{b}$ & $6.99 \pm 1.88^{\mathrm{a}}$ & $7.11 \pm 2.32^{b}$ & $9.89 \pm 2.64^{b}$ \\
\hline Group4 & $0.53 \pm 0.67^{\mathrm{a}}$ & $3.02 \pm 0.62^{\mathrm{c}}$ & $9.13 \pm 1.34^{c}$ & $9.22 \pm 1.73^{\mathrm{c}}$ & $10.45 \pm 2.71^{\mathrm{c}}$ & $12.44 \pm 2.01^{\mathrm{c}}$ \\
\hline $\begin{array}{c}\text { Kruskal-wallis } \\
\text { Test (p) }\end{array}$ & 0.000 & 0.000 & 0.000 & 0.045 & 0.000 & 0.000 \\
\hline
\end{tabular}

Glucose concentration, $\mathbf{m g} / \mathbf{d l}$ (mean \pm standard deviation) Mann-Whitney test: Means with the same superscript letters within each column are not significantly different at $\mathrm{P} \geq 0.05$

Table 2 : Time interval Related Glucose Leakage

\begin{tabular}{|c|c|c|c|c|}
\hline TIME & Group1 & Group2 & Group3 & Group4 \\
\hline Day1 & $0.52 \pm 1.31^{\mathrm{a}}$ & $0.00 \pm 0.32^{\mathrm{a}}$ & $0.00 \pm 0.00^{\mathrm{a}}$ & $0.53 \pm 0.67^{\mathrm{a}}$ \\
\hline Week1 & $5.02 \pm 1.51^{\mathrm{b}}$ & $1.34 \pm 1.33^{\mathrm{a}}$ & $1.23 \pm 1.21^{\mathrm{a}}$ & $3.02 \pm 0.62^{\mathrm{b}}$ \\
\hline Week2 & $11.02 \pm 2.61^{\mathrm{c}}$ & $5.62 \pm 1.53^{\mathrm{b}}$ & $6.02 \pm 2.72^{\mathrm{b}}$ & $9.13 \pm 1.34^{\mathrm{c}}$ \\
\hline Week3 & $13.32 \pm 0.62^{\mathrm{d}}$ & $7.72 \pm 0.11^{\mathrm{c}}$ & $6.99 \pm 1.88^{\mathrm{b}}$ & $9.22 \pm 1.73^{\mathrm{c}}$ \\
\hline Week4 & $15.66 \pm 4.57^{\mathrm{e}}$ & $7.98 \pm 1.93^{\mathrm{c}}$ & $7.11 \pm 2.32^{\mathrm{b}}$ & $10.45 \pm 2.71^{\mathrm{c}}$ \\
\hline Week6 & $18.43 \pm 3.83^{\mathrm{f}}$ & $10.22 \pm 3.51^{\mathrm{d}}$ & $9.89 \pm 2.64^{\mathrm{c}}$ & $12.44 \pm 2.01^{\mathrm{d}}$ \\
\hline Friedmann Test (p) & 0.000 & 0.000 & 0.000 & 0.000 \\
\hline
\end{tabular}

Glucose concentration, $\mathbf{m g} / \mathbf{d l}$ (mean \pm standard deviation) Wilcoxon Signed Ranks test: Means with the same superscript letters within each column are not significantly different at $\mathrm{P} \geq 0.05$ 


\section{DISCUSSION}

In the present study, the leakage along root canal fillings was measured by the glucose penetration method, which is simple and could give reliable quantitative leakage measurements. In the present study, glucose was selected as the tracer because it is of small molecular size $(\mathrm{MW}=180 \mathrm{Da})$ and is a nutrient for bacteria. If glucose could enter the canal from the oral cavity, bacteria that might survive root canal preparation and obturation could multiply and potentially lead to periapical inflammation. Glucose, therefore, was thought to be more clinically relevant than other tracers used in microleakage tests. Quantitative analysis of leakage was possible by determining the concentration of glucose in the apical reservoir that leaked through the filled root canal. ${ }^{14} \mathrm{To}$ determine the concentration of glucose, the enzymatic glucose oxidase method was chosen because it provided the ultimate degree of specificity and high sensitivity when compared with other methods, such as copper or ferricyanide methods. With this method, glucose is oxidized by the enzyme glucose oxidase in the presence of oxygen to gluconic acid with formation of hydrogen peroxide. ${ }^{15}$ Then in the presence of a peroxidase enzyme, a chromogenic oxygen acceptor (4-aminoantipyrine and phenol) is oxidized by the hydrogen peroxide, resulting in the formation of a red product (oxidized chromogen). The quantity of this oxidized chromogen is proportional to the glucose present initially in the first reaction, which quantity is determined by spectrophotometry. With this model, it was possible to quantify the endodontic microleakage continuously over time. The amount of microleakage was the cumulative value of leaked glucose. ${ }^{16}$ The reactivity of obturating materials with glucose could affect the results of the glucose leakage test. The results Shemesh et al. indicated that all materials used in the current study did not show glucose reactivity. ${ }^{17}$ The results of this study indicate that all obturation systems allow variable degrees of glucose leakage. Mandibular incisors with single oval-shaped canals were used in the present study with the purpose of evaluating the quality of root canal sealing in canals in which difficulties with the anatomy could complicate the root filling procedure. The studies of Pucci \& Reig (1944) and Mauger et al. (1988) reported the anatomical variety of those teeth.
The problem regarding irregular-shaped canals has been investigated previously. ${ }^{11}$ The oval canal shape may make it difficult to clean and fill (Wu et al. 2001). De-Deus et al reported that the irregular canal shape may influence the filling quality negatively. Kersten et al. (1986) pointed out that cold lateral compaction gutta-percha had been widely used in root canal treatment, although quality may vary depending on the root canal shape. ${ }^{11}$

The glucose leakage values of AH Plus groups with lateral condensation technique were significantly higher at the end of the experimental period. This might be explained by the fast setting and subsequent polymerization shrinkage of AH Plus sealer, ${ }^{18}$ the lack of bonding between this sealer and Gutta-percha the low penetration ability of this sealer within the dentinal tubules ${ }^{19}$ and its hydrophobic property that prevents good adaptation of to the incompletely dried canal. $^{20}$ Least leakage is seen in group 2 and 3 attributed to many reasons. The SmartSeal system (Prosmart - DRFP Ltd., Stamford, UK). The system consists of obturation points (C-points) containing a polyamide core with an outer bonded hydrophilic polymer coating and an accompanying sealer Smartpaste Bio. The endodontic points are designed to expand laterally without expanding axially by absorbing residual water from the instrumented root canal space and the naturally present moisture in the dentinal tubules. ${ }^{21}$ The inner core of Pro-points is a mix of two proprietary nylon polymers: Trogamid $\mathrm{T}$ and Trogamid CX. The polymer coating is a cross-linked copolymer of acrylonitrile and vinylpyrrolidone which has been polymerised and crosslinked using allyl methacrylate and a thermal initiator. The lateral expansion of Pro-points is claimed to occur nonuniformly with the expand-ability depending on the extent to which the hydrophilic polymer is prestressed (i.e., contact with a canal wall will reduce the rate or extent of polymer expansion). ${ }^{4}$ Bio-ceramic impregnated Gutta-Percha and Endosequence BioCeramic Sealer, owing to its hydrophilic property and nano-particle composition has also shown comparable microleakage to Smart-seal system. Bioceramic root canal sealers also exhibit chemical bonding to root canal dentin walls as well as its corresponding Biozeramic particle impregnated Gutta-Percha. ${ }^{22}$ Group 4 Resilon/RealSeal was expected to show less leakage 
in comparison but leakage was significantly higher than groups 2 and 3. Resilon is a polymer-based thermoplastic resin containing bioactive glass, bismuth oxychloride, barium sulfate, and radiopaque fillers. ${ }^{23}$ Many advantages of Resilon (SybronEndo, Orange, CA) have been reported, which include reduction in post-endodontic leakage. This advantage has been attributed to the monoblock concept. Secondary monoblocks are those that have two circumferential interfaces, one between the cement and dentin and the other between cement and the core material. In a root canal the $\mathrm{C}$ factor can be more preponderant than 1000 . Hence, any polymerizing endodontic sealer would be subjected to greater volume of polymerization stresses during the setting process, resulting in debonding and gap formation along the periphery of the root filling ${ }^{24}$ and thus can be a contributing factor for the increased leakage seen in this group. Therefore, inspite of the hydrophilic nature of Resilon, leakage was significantly more than other hydrophilic groups.

\section{CONCLUSION}

Hydrophilic groups have shown significantly lesser leakage as compared to the gold standard hydrophobic Gutta-Percha Obturation system. Furthermore studies would be required to assess the hydrophilic nature of the recent obturation systems.

\section{REFERENCES}

1. Sund qvist G, Figdor D, Persson S, Sjögren U. Microbiologic analysis of teeth with failed endodontic treatment and the outcome of conservative re-treatment. Oral Surg Oral Med Oral Pathol Oral Radiol Endod 1998;85:86-93.

2. Gordon MP, Love RM, Chandler NP. An evaluation of.06 tapered gutta-percha cones for filling of .06 taper prepared curved root canals. Int Endod J 2005;38:87-96.

3. Hess D, Solomon E, Spears R, He J. Retreatability of a bioceramic root canal sealing material. J Endod 2011;37:1547-9.

4. Highgate DJ, Lloyd JA. Expandable/contractable composition for surgical or dental use. United States Patent Number 7,210,935; May 1, 2007.

5. Shipper G, Ørstavik D, Teixeira FB, Trope M. An evaluation of microbial leakage in roots filled with a thermoplastic synthetic polymer-based root canal filling material Resilon. $\mathrm{J}$ Endod 2004;30:342-7.

6. Shipper G, Teixeira FB, Arnold RR, Trope M. Periapical inflammation after coronal microbial inoculation of dog roots filled with gutta-percha or Resilon. J Endod
2005;31:91-6.

7. Teixeira FB, Teixeira EN, Thompson JY, Trope M. Fracture resistance of roots endodontically treated with a new resin filling material. J Am Dent Assoc 2004; 135:646-52.

8. Mauger MJ, Schindler WG, Walker WA. An evaluation of canal morphology at different levels of root resection in Mandibular Incisors. J Endod 1998;24:607-9.

9. Juhasz A, Verdes E, Tokes L, Kobor A, Dobo-Nagy C. The influence of root canal shape on the sealing ability of two root canal sealers. Int Endod J 2006;39:282-6.

10. Wu MK, Wesselink PR. A primary observation on the preparation and obturation of oval canals. Int Endod $\mathrm{J}$ 2001;34:137-41.

11. De-Deus G, Murad CF, Reis CM, Gurgel-Filho E, Coutinho Filho T. Analysis of the sealing ability of different obturation techniques in oval-shaped canals: a study using a bacterial leakage model. Braz Oral Res 2006;20:64-9.

12. Xu Q, Fan MW, Fan B, Cheung GS, Hu HL. A new quantitative method using glucose for analysis of endodontic leakage. Oral Surg Oral Med Oral Pathol Oral Radiol Endod 2005;99:107-11.

13. Wu M-K, Wesselink PR. Endodontic leakage studies reconsidered. Part I. Methodology, application and relevance. Int Endod J 1993;26:37-43.

14. Wu M-K, Wesselink PR. Endodontic leakage studies reconsidered. Part II. Methodology, application and relevance. Int Endod J 1993;27:38-44.

15. Canalda-Sahli C, Brau-Aguade E, Sentis-Vilalta J, AguadeBruix $\mathrm{S}$. The apical seal of root canal sealing cements using a radionuclide detection technique. Int Endod J 1992;25:2506.

16. Bishop ML, Duben-Engelkirk JL, Fody EP. Clinical chemistry principles, procedures, correlations. 2nd ed. Philadelphia: Lippincott; 1985. pp. 307-9.

17. Shemesh H, Souza EM, Wu MK, Wesselink PR. Glucose reactivity with filling materials as a limitation for using the glucose leakage model. Int Endod J 2008;41:869-72.

18. Zmener O, Spielberg C, Lamberghini F, Rucci M. Sealing properties of a new epoxy resin-based root-canal sealer. Int Endod J 1997;30:332-4.

19. De-Deus G, Brandão MC, Fidel RA, Fidel SR. The sealing ability of guttaflow in oval-shaped canals: An ex vivo study using a polymicrobial leakage model. Int Endod $\mathrm{J}$ 2007;40:794-9.

20. Roggendorf MJ, Ebert J, Petschelt A, Frankenberger R. Influence of moisture on the apical seal of root canal fillings with five different types of sealer. J Endod 2007;33:31-3.

21. Highgate DJ, Frankland JD. Deformable polymeric compositions. United States Patent Number 4,565,722; January 21, 1986.

22. Sagsen B, Ustun Y, Pala K, Demirbuga S. Resistance to fracture of roots filled with different sealers. Dent Mater J 2012;31:528-32.

23. Aptekar A, Ginnan K. Comparative analysis of microleakage and seal for 2 obturation materials: Resilon/Epiphany and gutta-percha. J Can Dent Assoc 2006;72:245-245d.

24. Tay FR, Loushine RJ, Lambrechts P, Weller RN, Pashley DH. Geometric factors affecting dentin bonding in root canals: a theoretical modeling approach. J Endod 2005;31:584-9. 